\title{
BMJ Open Supporting community health workers in fragile settings from a gender perspective: a qualitative study
}

\author{
Joanna Raven (D) , ${ }^{1}$ Haja Wurie, ${ }^{2}$ Amuda Baba, ${ }^{3}$ Abdulai Jawo Bah, ${ }^{4}$ Laura Dean, ${ }^{1}$ \\ Kate Hawkins, ${ }^{5}$ Ayesha Idriss, ${ }^{4}$ Karsor Kollie, ${ }^{6}$ Gartee E Nallo, ${ }^{7}$ Rosie Steege, ${ }^{1}$ \\ Sally Theobald ${ }^{1}$
}

To cite: Raven J, Wurie $\mathrm{H}$, Baba A, et al. Supporting community health workers in fragile settings from a gender perspective: a qualitative study. BMJ Open 2022;12:e052577. doi:10.1136/ bmjopen-2021-052577

- Prepublication history and additional supplemental material for this paper are available online. To view these files, please visit the journal online (http://dx.doi.org/10.1136/ bmjopen-2021-052577).

Received 27 April 2021 Accepted 12 January 2022

Check for updates

(c) Author(s) (or their employer(s)) 2022. Re-use permitted under CC BY-NC. No commercial re-use. See rights and permissions. Published by BMJ.

For numbered affiliations see end of article.

Correspondence to

Dr Joanna Raven;

joanna.raven@|stmed.ac.uk

\section{ABSTRACT}

Objective To explore how gender influences the way community health workers (CHWs) are managed and supported and the effects on their work experiences. Setting Two districts in three fragile countries. Sierra Leone-Kenema and Bonthe districts; Liberia — two districts in Grand Bassa county one with international support for CHW activities and one without: Democratic Republic of Congo (DRC) - Aru and Bunia districts in Ituri Province.

Participants and methods Qualitative interviews with decision-makers and managers working in community health programmes and managing $\mathrm{CHWs}(\mathrm{n}=36)$; life history interviews and photovoice with CHWs ( $n=15$, in Sierra Leone only).

Results While policies were put in place in Sierra Leone and Liberia to attract women to the newly paid position of CHW after the Ebola outbreak, these good intentions evaporated in practice. Gender norms at the community level, literacy levels and patriarchal expectations surrounding paid work meant that fewer women than imagined took up the role. Only in DRC, there were more women than men working as $\mathrm{CHWs}$. Gender roles, norms and expectations in all contexts also affected retention and progression as well as safety, security and travel (over long distance and at night). Women CHWs also juggle between household and childcare responsibilities. Despite this, they were more likely to retain their position while men were more likely to leave and seek better paid employment. CHWs demonstrated agency in negotiating and challenging gender norms within their work and interactions supporting families.

Conclusions Gender roles and relations shape CHW experiences across multiple levels of the health system. Health systems need to develop gender transformative human resource management strategies to address gender inequities and restrictive gender norms for this critical interface cadre.

\section{INTRODUCTION}

Achieving Universal Health Coverage and the Sustainable Development Goals (SDGs), rests on the efforts and actions taken in fragile and conflict-affected settings (FCAS), where approximately two billion people are estimated to live. ${ }^{1}$ These settings are often

\section{Strengths and limitations of this study}

- This study is a gender analysis of the interplay between community health workers (CHWs), their communities and the health systems in fragile and conflict-affected settings.

- Gender roles, norms and expectations in fragile contexts affected selection, retention and progression as well as safety, security and travel of CHWs.

- The gender transformative potential of the CHW policies in the three study contexts is limited; health systems need to develop gender transformative human resource management strategies to address gender inequities and restrictive gender norms for this critical interface cadre.

- As the study focused on the perspectives of CHWs, decision makers and manager, the perspectives of the community and patients were missed; only in Sierra Leone, CHWs were included in the research process.

characterised by weak health systems, acute human resource shortages and poor health indicators. Access to equitable and quality healthcare services is central to strengthening health systems and the social fabric in these contexts. ${ }^{2}$

Human resources for health underlay the expansion of, and access to, quality health services. Sierra Leone, Liberia and Democratic Republic of Congo (DRC) all have a low density of higher cadre healthcare workers. Thus, the support of close-to-community care providers, such as community health workers (CHWs), drug distributors, village midwives and traditional birth attendants, can bridge the gap between poor, marginalised and underserved households and the health system. ${ }^{3}$

CHWs are embedded within their communities and make critical contributions to health systems in FCAS. ${ }^{4}$ In the drive to achieve the SDGs, there is renewed focus on the contribution of CHWs. ${ }^{5}$ To support 
their contribution, CHWs should be integrated into the overall health system, with effective human resource management (HRM) systems and supporting strategies. ${ }^{46}$ HRM strategies are influenced by context, sociocultural factors and gender norms. ${ }^{7-9}$ Gender roles and relations are context embedded and dynamic, shaping the social determinants of health and the experiences of CHWs.

CHWs are strategically placed-if managed and supported effectively-to also serve as change agents, addressing harmful sociocultural and gender norms from within communities. ${ }^{31011}$ There is emerging evidence that explains the gender dynamics that they are working within $^{91213}$ as well as increasing evidence on gender inequities within higher levels of the health workforce. ${ }^{14}$ To date, there is limited context-specific gender analysis of the interplay between CHWs, their communities and the health system in FCAS. Understanding this interplay is critical to the development and implementation of HRM strategies that will support CHWs.

In this paper, we present three FCAS case studies on CHWs-from Sierra Leone, Liberia and DRC_-to explore and understand the gendered dimensions of HRM, from the perspectives of key stakeholders and CHWs (the latter in Sierra Leone only). All three countries have experienced conflict, fragility and epidemics, which have disrupted their health systems. In Sierra Leone and Liberia (both postconflict), the 2014-2016 Ebola outbreak exposed weaknesses in the health system and lack of trust between communities and health system. ${ }^{16-19}$ DRC has recently experienced an Ebola outbreak; and all three countries are currently affected by the COVID-19 pandemic.

Health workers identified that during and after the Ebola outbreak, there was a need to build links and trust between health systems and communities and that CHWs were crucial to this. ${ }^{16}$ CHWs played a critical role during the Ebola outbreak in managing the spread of the virus. ${ }^{1720}$ This was the impetus for new CHW policies to support their integration into the wider health system, which were rolled out in Liberia ${ }^{21} 22$ and Sierra Leone. ${ }^{23}$ However, there is limited evidence from these settings on how gender influences health workers' experience to guide new policy development. Developing the evidence base here from a gender and equity perspective is, therefore, critical. DRC too suffers from a severe shortage of healthcare personnel and CHWs play an important role in providing health services to communities in insecure areas; they are often the only healthcare workers who stay in communities in times of crisis. ${ }^{24}$

Following dialogue with key stakeholders, this research explores how gender influences the way CHWs are managed and supported and the effects on their work experiences. This study offers recommendations for more gender equitable and transformative HRM strategies that support CHWs within FCAS.

\section{METHODS}

\section{Study design}

We used qualitative research methods to explore how gender influences the way CHWs are managed and supported, and the effects on their work experiences in three countries. This generated in-depth, contextual information about CHWs', managers' and decisionmakers' experiences and perceptions. ${ }^{25} 26$ In Sierra Leone, the in-depth study, we used four methods: document review, key informant interviews with decision-makers and managers, life history interviews and photovoice with CHWs. In contrast, the research in Liberia and DRC was designed as a rapid appraisal of the current situation in these two settings, which included policy review and interviews with key staff knowledgeable about the CHW programmes. We used four methods of data collection, which allowed us to compare and contrast what is written about management of CHWs (document review) and what actually happens in practice drawing on the different perspectives of CHWs, decision-makers and managers (key informant interviews, life history interviews and photovoice). This helped with triangulation and ensuring the trustworthiness of the data.

\section{Research team}

The research was led by the lead author, an experienced qualitative researcher with a $\mathrm{PhD}$ in health systems research, working with teams in DRC, Liberia and Sierra Leone who are experienced at qualitative data collection and analysis and working with CHWs' health managers and decision-makers. By involving all authors, with different professional, personal and geographical backgrounds, we ensured that different interpretations and perspectives were incorporated in the analysis.

\section{Study setting}

In each country context, we purposively selected two districts to capture diversity of settings and to include contexts where we had pre-existing relationships. In Sierra Leone, this was Kenema in the Eastern Province with urban and rural areas and heavily affected by the Ebola outbreak and Bonthe in the Southern Province, which is hard to reach, riverine with several islands and less affected by the Ebola outbreak. In Grand Bassa county in Liberia, two districts were selected one with international support for CHW activities, and one without. As DRC has decentralised health management to the provinces, we conducted the study at provincial level and in two districts-Aru which is mainly rural, and Bunia which is urban.

\section{Data collection}

The data were collected over a period of 6 months between October 2017 and April 2018.

Document review: we reviewed key documents from the Ministries of Health in each country including CHW policies, guidelines and training materials to answer key questions: Are gender considerations included in the 
Table 1 Participants for key informant interviews

\begin{tabular}{lcccc}
\hline & Sierra Leone & Liberia & DRC & Total \\
\hline Decision makers at national and provincial level & $4(2 \mathrm{~F} ; 2 \mathrm{M})$ & $3(3 \mathrm{M})$ & $2(1 \mathrm{~F} ; 1 \mathrm{M})$ & $9(3 \mathrm{~F} ; 6 \mathrm{M})$ \\
District level managers & $4(1 \mathrm{~F} ; 3 \mathrm{M})$ & $3(3 \mathrm{M})$ & $3(1 \mathrm{~F} ; 2 \mathrm{M})$ & $10(2 \mathrm{~F} ; 8 \mathrm{M})$ \\
Facility and community level managers & $10(3 \mathrm{~F} ; 7 \mathrm{M})$ & $4(2 \mathrm{~F} ; 2 \mathrm{M})$ & $3(1 \mathrm{~F} ; 2 \mathrm{M})$ & $17(6 \mathrm{~F} ; 11 \mathrm{M})$ \\
Total & 18 & 10 & 8 & $36(11 \mathrm{~F} ; 25 \mathrm{M})$ \\
\hline
\end{tabular}

$\mathrm{F}=$ female; $\mathrm{M}=$ male.

documents? If yes, how? How are female and male CHWs managed and supported in their work? We extracted, summarised and synthesised text for each question.

Key informant interviews with decision-makers and managers: Using topic guides adapted for each country (see online supplemental file 1), we explored how CHWs are managed and supported. We selected decision-makers (representatives of government departments and Non Governmental Organisation programmes who make decisions about how the CHW programmes are run, and how CHWs are managed and supported) and managers based on their involvement in developing community health policies, knowledge of community health programmes and managing CHWs. Details of the decision-makers and managers included in each setting are provided in table 1. In Sierra Leone, which is the in-depth study, we conducted 18 key informant interviews. In the rapid situation analysis of DRC and Liberia, we conducted between 8 and 10 interviews. The research teams in each country conducted the interviews in the participants' workplaces, in English or Liberian English (Liberia), French (DRC) and English or Krio (Sierra Leone). The interviews lasted between 40 and $90 \mathrm{~min}$ and were recorded following consent of the participants.

Life history interviews with CHWs (Sierra Leone only): men and women CHWs (from different villages, with a range of ages and length of experience as a CHW (table 2)) provided a personal account of their life and career over time. ${ }^{27}$ Researchers then explored their career with probing questions around their gendered experiences as a CHW, support and HRM strategies, relationships with existing cadres in the health system and coping strategies (see online supplemental file 1 for the topic guide). The interviews were conducted in Krio, in private rooms in the health facilities.

Photovoice: each CHW selected for the life history interview was included in the photovoice method. CHWs were trained on how to use a camera to take photographs of their work, work environment and interactions with the health system over a 3-month period, and on how to take verbal consent. The CHWs took photographs of people and their possessions after gaining their verbal consent. CHWs were encouraged to take photographs that did not reveal the identity of the people being photographed. In a reflective meeting, CHWs discussed the photographs they took with the research team and peers and selected those that best reflected their work and context. All CHWs then came together to present their photos to the group guided by the questions: What is happening in the photo? Why did you take this photo? How does this photo affect us? and What can we do about it? This generated group discussion and problemsolving. The discussion was recorded following permission.

\section{Data analysis}

The country teams transcribed the recordings verbatim and where necessary translated into English. They checked the verbatim transcripts and recordings with the English transcript which minimised loss of meaning.

We used the thematic framework approach to analyse the qualitative and document review data. ${ }^{29}$ All authors participated in the analysis, which brought diverse perspectives and interpretations. We developed one coding index (online supplemental file 2) from the topic guides, research objectives, emerging themes and domains from Steege $e t a l$ s conceptual framework (figure 1). This framework shows how gender roles, relations and norms shape, and, in turn, are shaped, by the individual, community and health system levels, the relationship between them and the complex interplay within the broader health and political environment. ${ }^{7}$ The country teams applied the framework to the transcripts and data and developed charts for each code. The lead author then identified the initial themes through review of the initial analysis in each country and then shared these with the other authors to interrogate and refine. Consensus on key themes (eg,

Table 2 Participants for life history interviews

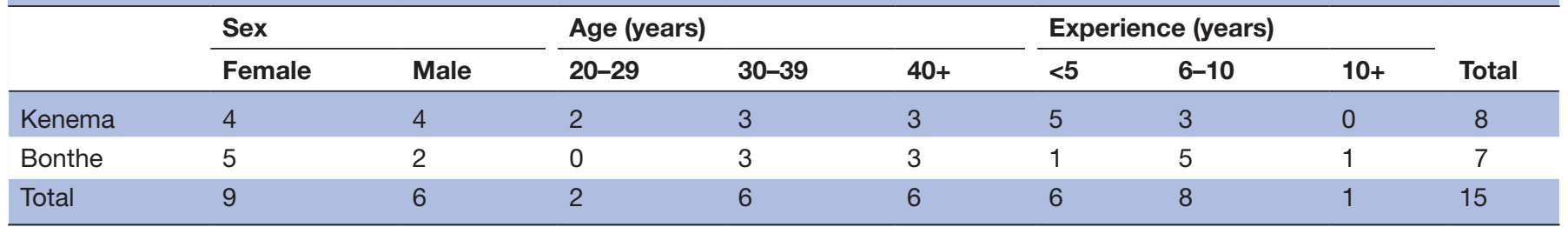




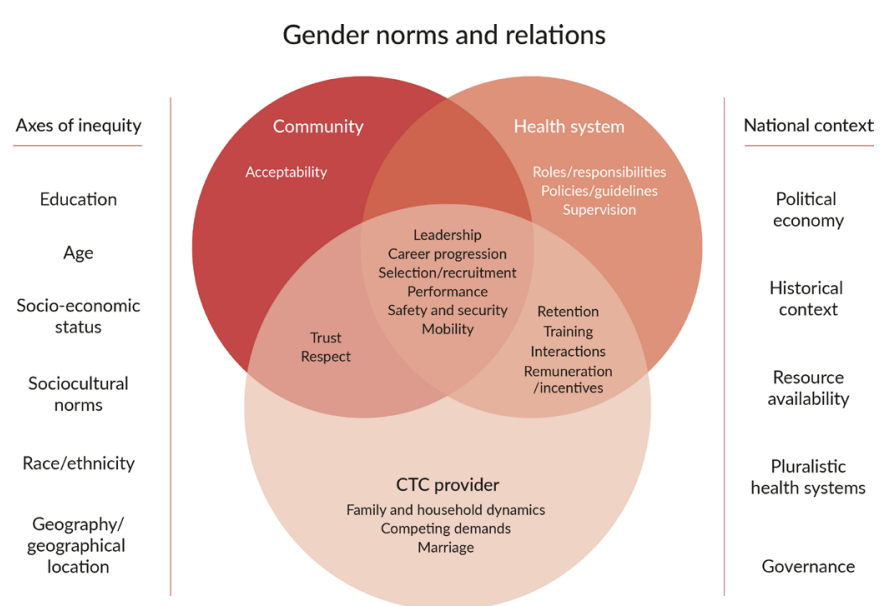

Figure 1 How gender shapes CHWs interface between community and health system. CHW, community health worker; CTC provider, Close to Community provider.

selection and recruitment, retention and remuneration, safety, security and travel, community norms and preferences and addressing community gender norms) across contexts was reached through iterative reflection, which involved the authors reviewing the themes, checking that the data support the themes and adapting them. This was done by dialogue through in-person meetings, e-mail and Skype, over a period of several months and consolidated in an analysis and writing workshop in Sierra Leone with all country teams present.

\section{Patient and public involvement}

Patients and/or the public were not involved in the design, conduct, reporting or dissemination plans of this research.

\section{FINDINGS}

The results are informed by Steege et al's framework ${ }^{7}$ (figure 1) and link to the key concepts in this framework. They begin with an overview of the evolution of the CHW policies to provide the contexts in which the findings are situated. We then move onto key HRM functions (selection and recruitment, retention and remuneration, safety, security and travel provision), an overview of CHW and community relationships and CHWs' agency in challenging gender norms.

\section{Summary of CHW policies in Sierra Leone, Liberia and DRC}

In Sierra Leone, the CHW programme was rolled out nationwide and 15000 people were trained to provide a basic package of services at the community level with a focus on gender. ${ }^{23}$ Services included-reproductive, maternal, newborn and child health, integrated community case management of sick children and infection prevention and control.

In Liberia, the policy focused on the development of Community Health Assistant cadre (CHAs-a type of CHW) trained to deliver a package of preventive, curative, promotive, rehabilitative and palliative services as well as health surveillance. CHAs are supervised by Community Health Services Supervisors-a cadre of health worker who have been formally trained, for example, a nurse, physician assistant or midwife. Previous cadres of community health volunteers (CHVs), for example, community drug distributors remain in operation and were supervised by CHAs. ${ }^{21}$

In the DRC, there is no overarching CHW programme, but CHWs are organised into three categories: site CHWs (providing a package of community activities, such as distribution of Ivermectin and contraceptives, case management of malaria, diarrhoea and respiratory infections), promotional CHWs (providing health education to communities) and disease-programme CHWs (providing specific services for the programme such as the Expanded Programme on Immunisation). ${ }^{30-32}$

We use the term CHW to include CHWs in Sierra Leone and DRC and CHAs in Liberia. None of these CHWs are salaried, but they receive allowances. In Sierra Leone, CHWs should receive 100000 Leones plus 50 000-80 000 Leones for transport and other logistics per month (equivalent of US\$20-US\$24); the minimum wage is 500 000 leones per month (equivalent of US\$67). In Liberia, each CHA should receive US $\$ 70$ per month, which is based on provision of a package of healthcare at the household level through a minimum of 4 hours of work/ day; the minimum wage is US\$75. In DRC, CHWs receive some financial compensation if they work for specific programmes, go to training events or from sales of health products such as bed nets. Table 3 provides a summary of the key findings from the policy review.

\section{Selection and recruitment of CHWs}

CHW policies were launched post-Ebola in Sierra Leone and Liberia to prioritise the selection of women as CHWs or CHAs. In both settings, this is due to the scope of CHWs' work, which largely focuses on women's health, maternal, new-born and child health.

All things being equal preference should be given to women, especially those who have worked with pregnant and new mothers (National Community Health Worker Policy, Sierra Leone, p21 $)^{23}$.

In Liberia, this prioritisation was further described by some key informants as being linked to gender roles within communities.

Men are always on the move, but women are the ones who stay home to look after home and family (National decision-maker, man, Liberia).

In DRC, there are perceived equal opportunities for women and men in the CHW selection process. Human resource policy as set by the Economic and Social Council of DRC in 1995 states that at least $30 \%$ of health worker posts, including CHWs, should be occupied by women. ${ }^{33}$ However, the policy does not state how this can be achieved in practice. 
Table 3 Summary of findings from policy review

\begin{tabular}{|c|c|c|c|}
\hline & Sierra Leone & Liberia & DRC \\
\hline CHW programmes & $\begin{array}{l}\text { Rolled out nationwide } \\
15000 \mathrm{CHWs} \text { trained to } \\
\text { provide basic package of } \\
\text { services at community level }\end{array}$ & $\begin{array}{l}\text { CHAs trained to deliver a package of } \\
\text { preventive, curative, rehabilitative and } \\
\text { palliative services } \\
\text { CHAs are supervised by CHSS } \\
\text { Previous cadres of community health } \\
\text { volunteers remained in operation and } \\
\text { were supervised by CHAs }\end{array}$ & $\begin{array}{l}\text { No overarching CHW programme } \\
\text { Three categories: site CHWs; } \\
\text { promotional CHWs; disease } \\
\text { programme }\end{array}$ \\
\hline Remuneration & $\begin{array}{l}\text { Each CHW should receive: } \\
100000 \text { plus } 50000 \text { to } 80000 \\
\text { Leones for transport and other } \\
\text { logistics per month (equivalent } \\
\text { of US\$20-24) }\end{array}$ & $\begin{array}{l}\text { Each CHA should receive US } \$ 70 \text { per } \\
\text { month through a minimum of } 4 \text { hours } \\
\text { work per day }\end{array}$ & $\begin{array}{l}\text { Financial compensation for work on } \\
\text { specific programmes, attend training, } \\
\text { or from sales of health products }\end{array}$ \\
\hline
\end{tabular}

CHA, Community Health Assistant; CHSS, Community Health Services Supervisors; CHW, community health worker; DRC, Democratic Republic of Congo.

Polices in Liberia and Sierra Leone support the selection of women, nevertheless, there are many more male CHWs than female CHWs in both settings. In contrast, there are more women taking on the CHW role in DRC (table 4).

Policy ideals in terms of selection, attraction and recruitment were mediated in practice by societal and gender norms. In Liberia, it was reported that community-based selection processes favoured men. Some informants described this as difficult to change as it was viewed as a community norm or preference to prioritise men over women.

What satisfies the community... and if the community bring a male and I tell them no, they won't feel good because it's the person they feel comfortable with (facility manager, woman, Liberia).

In Sierra Leone, some participants believed that this correlates with men's greater capacities due to having more education, more physical stamina and greater availability to work because they are not expected to do domestic labour.

Men can work harder than some of the women, especially walking long distances (community manager, man, Sierra Leone)
In both countries, it was reported that male partners and husbands did not want their wives to be employed, or to engage in community work. This was said to be a reason for the low numbers of women CHWs. Women experience limits on their mobility, often due to fear of sexual or gender-based violence.

In DRC, there are more women CHWs, where there were women's associations. These associations advocate for women and influence husbands' and relatives' attitudes towards granting women permission to join the CHW programme.

Here in our health district, where you find nearly half of CHWs are female, there are women associations, but where there are no women associations, you find that there are more male community health workers (district manager, man, DRC).

Literacy was a requirement for CHWs in DRC and Liberia. In general, men were more literate, highlighting how the education of boys is prioritised due to entrenched patriarchal preference. County and district-level informants in Liberia described how:

In the interior...boys' education is prioritised over girls', with girls remaining in the kitchen (community manager, woman, Liberia).

\begin{tabular}{|c|c|c|c|}
\hline Country & Total number of CHWs & Number of female CHWs (\%) & Number of male CHWs \\
\hline Liberia (Grand Bassa County) & 101 & $10(10 \%)$ & $91(90 \%)$ \\
\hline DRC (Ituri Province-Aru District) & 840 & $403(48 \%)$ & $437(52 \%)$ \\
\hline Sierra Leone (country) & 13935 & $3283(24 \%)$ & $10652(76 \%)$ \\
\hline
\end{tabular}

Sources: CHW Hub at Ministry of Health and Sanitation, Sierra Leone; Ministry of Health, Grand Bassa County Health Team, Community Health Department Records; Central Office of Bunia Health District; Central Office of Aru Health District.

$\mathrm{CHW}$, community health worker; DRC, Democratic Republic of Congo. 
Literacy challenges are compounded in FCAS, where education has historically been disrupted due to conflict. This places women at an even greater disadvantage. To overcome these challenges, and to try and continue to prioritise women in CHW selection, informants in Liberia and Sierra Leone described working with women (and some youth) to try and increase their literacy levels.

Where women and youth have been unable to read and write they have been encouraged to join the elders' educational programme so that they can be incorporated into the programme (national decisionmaker, man, Liberia).

This has helped to some degree with, 'some women who as a result of literacy support linked to the CHA programme have completed school and are in midwifery school (community manager, woman, Liberia). Informants believed that embedding literacy programmes within CHW training would support the participation of women and other people with literacy challenges.

\section{Retention and remuneration}

Key informants from all three settings and CHWs in Sierra Leone reported that retention of CHWs is shaped by gendered norms within households and communities.

As reflected in CHW selection processes, women's ability to work can be constrained by patriarchal hierarchies within the family. In many settings, women have domestic responsibilities, including housework and care for children and relatives. They juggle these roles with their CHW work, limiting the time they can spend at work and affecting their performance and retention.

As for female CHWs, especially married women, due to their family responsibilities, in most of the cases they arrive late, as they need to make sure they have covered home need. If they have a child who is unwell, that also affects their presence as they need to care for the child. To overcome it, we just make sure that we understand them, as when they are there, they are really productive (district manager, man, DRC).

In many settings, men have the final say in how women allocate their time to household work and CHW work, and ultimately whether women stay in the role of CHW.

Sometimes, their husbands are not happy as we engage their wives for volunteer work for a long time (facility manager, woman, DRC).

Male CHWs are more likely to find a paid job and leave their role as CHW. They are expected to be the breadwinners of the family (and sometimes multiple families), and, therefore, seek paid work. This is more frequent, where there are more employment opportunities such as in the gold mining areas of Sierra Leone. On the other hand, woman CHWs were seen as being more stable, as 'they don't go away' (facility manager, man, Sierra Leone).

Demonstrating how gender intersects with marital status to determine the need for income-generating opportunities, women in female-headed households sought additional work, as they were, 'without a man to support' (CHW, woman, Sierra Leone).

Some felt that women, especially those who have worked as traditional birth attendants, were willing to provide care with no or ad hoc financial incentives.

If a woman chooses to become a CHW, she can do it genuinely. They don't disobey. Some had [worked] as TBAs (Traditional Birth Attendants) and have not been receiving anything (money) in the past, but they were still happy to do the job (facility manager, man, Sierra Leone).

To overcome the issue of attrition among men, respondents reported trying to replace them with new recruits. One facility manager (a woman) in DRC reported taking a different approach and providing income to male CHWs in the hope of assigning some value to the work that they do, 'I just have sometimes to use my own money to give them [male CHWs] so that they realise the expected work'. This approach, while innovative and pragmatic, reinforces the gender norms that exist within the community, suggesting that men's labour is worthier of payment than women's.

In many cases, women have limited opportunities for career progression due to literacy and mobility issues and gendered roles, which can be demotivating and result in attrition. As one respondent from the DRC noted:

Something surprising is that females are the majority, but men seem to be more active, and are more available to serve, and there are males who occupy responsibility positions (facility manager, woman, DRC).

This was also seen in Sierra Leone, where most peer supervisors (CHWs with additional training, allowances and responsibilities) are men, and women rarely perform this role because of lower literacy, lower education levels and gendered expectations and norms around leadership.

\section{Safety, security and travel}

Gender dynamics influence how CHWs travel around their communities and access households. In all settings, key informants and CHWs reported that women found it difficult to travel long distances for their work. This was due to social expectations of women and, ' $a$ reluctance of husbands to let their wives walk outside the community' (national decision-maker, man, Liberia).

These gendered expectations and restrictions lead women to different roles during campaign activities. One supervisor in Liberia described the ability of men to travel these longer distances unescorted and completing more work.

But maybe when it comes to distances, maybe there is a gender issue, because the female we are not strong to walk longer distances. So, when there is a campaign there are some distance and some hard-to-reach areas we will assign a male there because the female won't go. That's a gender issue. I think is reasonable 
because ... females are much lesser in strength than males. Males can cover a longer distance and feel normal, but female don't cover that distance and remain normal (facility manager, man, Liberia).

Long distances may require CHWs to stay in communities overnight. One manager in Liberia described that sometimes when she reached supervision locations, she had to stay overnight as it was dark and not safe for her to return.

We go in the field, we sleep in the field. I have to walk on seven hours distance to go for supervision, and then I have to supervise the CHAs on two hours. Before I come back, darkness will catch me and I will sleep there. No compensation. I spend more time in the field, so they should see about compensating me for accommodation and feeding. These are things that can really affect performance (community manager, woman, Liberia).

CHWs attend women during childbirth and sick children and adults during the night. This raises security concerns; in Sierra Leone and Liberia, male CHWs or relatives tended to escort the woman CHWs to households at night.

Transport costs incurred during CHW work may inadvertently favour men who have more income-generating opportunities. As one facility manager, a man, in DRC explained:

You know, sometimes they have to use their own means of transport even their money to organise activities, you know, this a bit challenging, and that might affect their performance.

\section{Community norms and preferences}

Key informants from all contexts, and CHWs from Sierra Leone, reported that gender norms shape both CHW and service acceptability. In all contexts, concerns were expressed about women's/communities' readiness to accept men working on sexual, reproductive and maternal health. In Liberia, many key informants reported that men CHAs find some health areas difficult to discuss with women, for example, pregnancy, sexual health or feminine hygiene and that community members would hide these issues.

For a man to go into detail about pregnancy with a woman, they will find it difficult. When [a man] comes she will just say I am not feeling well. But if she has any danger sign, maybe she has sore between her leg, she will [show the] female, but she will not be able to show it to the male (facility manager, man, Liberia).

In the DRC, key informants reported that women were perceived to be more able to counsel both men and women about health matters than men.
Well, female community health workers, we have them, yes because as I said before they have very good communication skills as far as dealing with women is concerned, they can better understand themselves. They are also able to communicate to men without any problem (Facility manager, man, DRC).

Key informants in Sierra Leone felt that some community members were suspicious of men CHWs and their motives for caring for women in the community. They were often accused of ulterior, sexual motives if talking to women in communities. This led to men and women CHWs being deployed in pairs.

Complaints from men that male CHWs are talking with pregnant women - thought they were wanting to have sexual relationship with her. If female CHWs do this there is no problem. [It's a] common problem. There was a time we held a meeting and decided that the men should not go alone but should be accompanied by a female so that all of us can do the work together; and go in the day and not at night (community manager, man, Sierra Leone).

\section{Can CHWs address gender norms in the community?}

Gender norms within the community shape communities' views of CHWs and service acceptability. We found emerging evidence of CHWs strategising and working together to address harmful gender norms that restrict health and wellbeing. They had not been formally trained to take on this role. Only in Sierra Leone did training include a limited focus on how gender shapes community norms and how gender should be considered during community entry and relationship building. In Sierra Leone, a district health manager reprimanded a man CHW for beating his wife as this contradicted the ethos of the programme.

In all contexts, it was believed that CHWs were well positioned to relay community concerns and health conditions to the health system, and that this could address negative gender norms. Key informants in DRC explained how CHWs were able to act as intermediaries to give women's voices a platform and to encourage women to express their concerns.

CHWs' willingness and ability to interact with and challenge harmful gender norms emerged most clearly through the photovoice methodology, which was used in Sierra Leone. Via their photos and facilitated group discussions, CHWs demonstrated agency in negotiating and challenging gender norms within their work. They supported each other in generating solutions to address gendered challenges. For example, CHWs discussed how to speak with community leaders and families about bed nets, so that they were not just used for men or for fishing but also for women and children. They explored approaches that encourage women to generate income for their family such as rearing poultry. They considered ways to support women who had been abandoned by partners and families, or grandmothers who were looking after Ebola orphans. 


\section{DISCUSSION}

\section{Summary of key findings}

Our study has focused on the HRM areas of selection, attraction, retention, career progression, roles and responsibilities, remuneration, safety, security and mobility. These are not isolated areas, but interrelated and shaped by context, trust, community acceptability, family and household dynamics and responsibilities (figure 1). In Liberia and Sierra Leone, new CHW policies were developed following the Ebola outbreak in recognition of the critical role this cadre plays. Policy preferences to select women CHWs evaporated in practice, when mediated by gender norms at the community level and patriarchal expectations surrounding paid work. Literacy was a requirement for CHWs in DRC and Liberia. In general, men were often more literate, highlighting how the education of boys is prioritised. Literacy challenges are further compounded in FCAS, where education has historically been disrupted due to conflict, placing women at an even greater disadvantage.

In FCAS, CHWs play an important role in bridging communities with the health system. Much of the role of CHWs focuses on reproductive health, and some individuals and communities prefer these services to be provided by a specific gender - with women providing services for women—as seen in other studies. ${ }^{12} 134$ Concerns and gendered norms and expectations around safety, security and travel, particularly evident in FCAS, can potentially limit selection of women into the CHW role and affect retention and progression too. This has been found in other studies. ${ }^{735-38}$ In FCAS, where livelihoods are often fragile, CHWs rely on the financial incentives provided for their role. However, these were unreliable, with men more likely to leave and seek better paid employment, while women remained as CHWs despite no or ad hoc provision of the allowances. Similar dynamics have been found in Mozambique. ${ }^{9}$ Women are less able to gain paid employment, and this is particularly the case in FCAS where education has been disrupted and options can be limited. In DRC, CHWs' remuneration is limited to ad hoc programme work, training allowances and sales of health commodities. This reinforces the view that unpaid CHW work is 'voluntary' and feminised labour. ${ }^{7}$

\section{Health systems reflect and build gender norms}

The health system is a creator of gender norms and is not just a reflection of them. ${ }^{39}$ Our analysis shows the limitations of the gender transformative potential of the CHW policies in the three study contexts. The absence of strong guidance and recommendations about gender transformation meant that new policies had limited utility in practice. There is a clear need to build on context-specific gendered norms and African feminisms and approaches here. Liberia, Sierra Leone and DRC are no strangers to conflict and the relation between male control of political and economic arenas is evident. ${ }^{40}$ Failing to take note of this complex political and feminist history, while developing health policy and specifically HR policies, is likely to sustain existing patriarchal dominance.
Understanding the particularities in FCAS conflicts is essential in order to be able to equitably, efficiently and effectively address gender issues within policies, management and support of CHWs. Health workers, and, in particular, CHWs, are in a key position to mediate many gender norms, which impact on health and well-being, as they are embedded and understand the context in which they work and live. ${ }^{39} \mathrm{CHWs}$ cannot support gender transformation unless support, and space is provided to enable them to reflect and imagine a better world in which they can safely rock the boat. The photovoice method created that space and gave insights into what is possible. Photovoice illustrates how CHWs were strategising and working individually and together to address harmful gender norms that restrict health and well-being. This approach showed that CHWs were well positioned to feedback communities' realities, concerns and priorities to the health system and form a feedback loop. ${ }^{41}$ This has been seen in other photovoice projects, for example, strengthening group dynamics as well as individual empowerment among women in a low-income districts of Madrid; and better understanding water, sanitation and hygiene behaviours and catalysing community-led solutions to change behaviours in Kenya. ${ }^{42} 43$

\section{Gender transformative HRM}

To be gender transformative, strategies to manage and support CHWs must address gender disparities in selection, retention, remuneration, performance and career progression (table 5).

\section{Limitations}

There are several limitations to the study. The focus on CHW, decision-makers and managers, means that perspectives of the community and patients were missed. Only in Sierra Leone, CHWs were included in the research process through life histories and photovoice and expanding these methods to understand CHWs (and community voice and perspectives) would be important going forward. Despite this, the range of methods and contexts included, and the gender analysis framework deployed, mean that generalisable findings that unpack how gender, power and hierarchy manifest in health systems and communities and recommendations in an under-researched area have been developed.

\section{CONCLUSION}

CHWs are a critical cadre that bridges the gap between communities and health systems, particularly in FCAS. A better understanding of their management through a gender lens is key for maximum impact and sustainability. There is a need for ongoing monitoring, evaluation and learning as CHW programmes continue. The COVID-19 pandemic, like other health systems shock before, has demonstrated the value of CHWs and their importance in responding, offering advice, support and care. This study provides the perspectives and voices of CHWs, managers and decisionmakers and offers recommendations for gender equitable 
Table 5 Gender transformative HRM strategies: suggestions and learning from our study

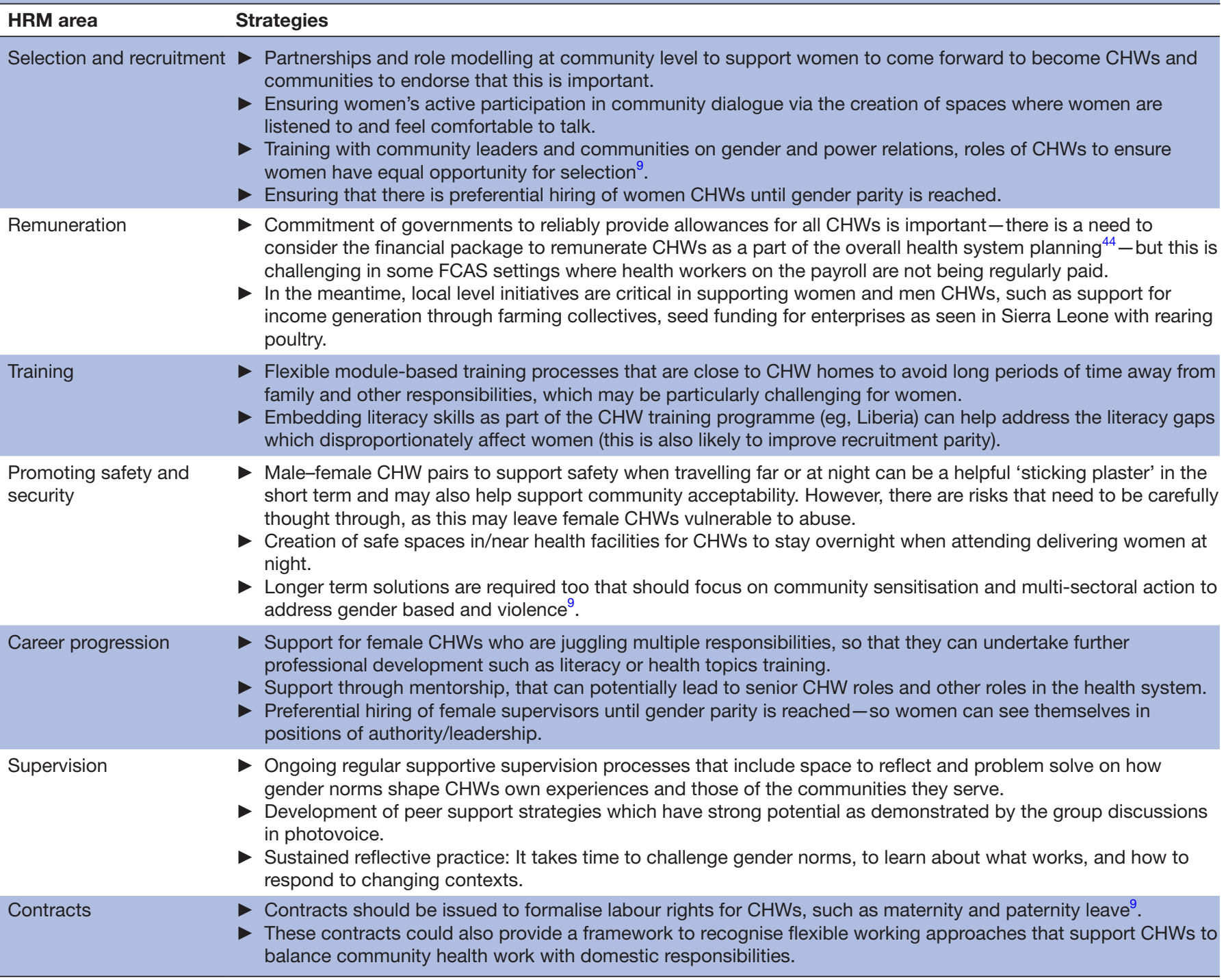

$\mathrm{CHW}$, community health worker; FCAS, fragile- and conflict-affected settings; HRM, human resource management.

and transformative HRM strategies that support community health systems.

\section{Author affiliations}

${ }^{1}$ Department of International Public Health, Liverpool School of Tropical Medicine, Liverpool, UK

${ }^{2}$ Department of Nursing, College of Medicine and Allied Health Sciences, University of Sierra Leone, Freetown, Sierra Leone

${ }^{3}$ Institut Panafricain de Santé Communautaire et Medecine Tropicale, Bunia, Democratic Republic of the Congo

${ }^{4}$ Department of Pharmacology, College of Medicine and Allied Health Sciences, University of Sierra Leone, Freetown, Sierra Leone

${ }^{5}$ Pamoja Communications, Brighton, UK

${ }^{6}$ Neglected Tropical Disease Program, Ministry of Health, Monrovia, Liberia

${ }^{7}$ University of Liberia Pacific Institute for Research and Evaluation, Monrovia, Liberia

Acknowledgements We thank all the research and workshop participants who shared their stories, knowledge and ideas so readily.

Contributors JR conceptualised and designed the study, coordinated the data collection, supported the analysis and interpretation of the data and drafted the manuscript; JR is responsible for the overall content as the guarantor. HW, Al, AJB contributed to the design of the study, collected analysed the data in Sierra Leone, and reviewed drafts of the manuscript. GEN, KK, LD contributed to the design of the study, collected and analysed the data in Liberia and reviewed drafts of the manuscript. $A B, R S$ contributed to the design of the study collected and analysed the data in DRC and reviewed drafts of the manuscript. KH contributed to the analysis and interpretation of the data, and reviewed drafts of the manuscript. ST contributed to the conceptualisation and design of the study, analysis and interpretation of the data, and reviewed drafts of the manuscript. All authors read and approved the final manuscript.

Funding This work was supported by the UK Department for International Development under Grant P0 5247.

Competing interests None declared.

Patient consent for publication Not applicable.

Ethics approval This study involves human participants and was approved by the Liverpool School of Tropical Medicine (Research protocol 17-044), the Multidisciplinary Research Centre for Development in Bunia, DRC (024/2017), the Sierra Leone Ethics and Scientific Review Committee, Ministry of Health and Sanitation and the University of Liberia PIRE Institutional Review Board (I0R0004203). Rigorous informed consent processes were followed: all participants were given verbal and detailed written information about the nature and purpose of the research before taking part; participants were made aware of their right to decline to answer questions and were assured that measures were in place to anonymise responses. All participants gave written consent. Interviews were 
conducted in private locations, and recordings were transferred to passwordprotected computers. They were then transcribed and anonymised, and the recordings were deleted. Participants gave informed consent to participate in the study before taking part.

Provenance and peer review Not commissioned; externally peer reviewed.

Data availability statement Data are available upon reasonable request. All datasets are available from the corresponding author on reasonable request.

Supplemental material This content has been supplied by the author(s). It has not been vetted by BMJ Publishing Group Limited (BMJ) and may not have been peer-reviewed. Any opinions or recommendations discussed are solely those of the author(s) and are not endorsed by BMJ. BMJ disclaims all liability and responsibility arising from any reliance placed on the content. Where the content includes any translated material, BMJ does not warrant the accuracy and reliability of the translations (including but not limited to local regulations, clinical guidelines, terminology, drug names and drug dosages), and is not responsible for any error and/or omissions arising from translation and adaptation or otherwise.

Open access This is an open access article distributed in accordance with the Creative Commons Attribution Non Commercial (CC BY-NC 4.0) license, which permits others to distribute, remix, adapt, build upon this work non-commercially, and license their derivative works on different terms, provided the original work is properly cited, appropriate credit is given, any changes made indicated, and the use is non-commercial. See: http://creativecommons.org/licenses/by-nc/4.0/.

\section{ORCID iD}

Joanna Raven http://orcid.org/0000-0002-4112-6959

\section{REFERENCES}

1 World Bank. World bank group strategy for fragility, conflict, and violence 2020-2025, 2020. Available: http://documents.worldbank. org/curated/en/844591582815510521/pdf/World-Bank-GroupStrategy-for-Fragility-Conflict-and-Violence-2020-2025.pdf [Accessed 04 Jan 2021]

2 ReBUILD. Working towards universal health coverage in post-conflict environments, 2014. Available: https://rebuildconsortium.com/media/ 1107/uhcbriefingfinal1.pdf [Accessed 04 Jan 2021].

3 Theobald S, MacPherson E, McCollum R, et al. Close to community health providers post 2015: realising their role in responsive health systems and addressing gendered social determinants of health. BMC Proc 2015;9:S8.

4 Raven J, Akweongo P, Baba A, et al. Using a human resource management approach to support community health workers: experiences from five African countries. Hum Resour Health 2015;13:45

5 Maher D. 'Leaving no-one behind': how community health workers can contribute to achieving the sustainable development goals. Public Health Action 2017;7:5.

6 Raven J, Wurie $\mathrm{H}$, Idriss $\mathrm{A}$, et al. How should community health workers in fragile contexts be supported: qualitative evidence from Sierra Leone, Liberia and Democratic Republic of Congo. Hum Resour Health 2020;18:58.

7 Steege R, Taegtmeyer M, McCollum R, et al. How do gender relations affect the working lives of close to community health service providers? empirical research, a review and conceptual framework. Soc Sci Med 2018;209:1-13.

8 Steege R, Hawkins K, Wurie H. Gender and community health worker programmes in fragile and conflict-affected settings. findings from Sierra Leone, the Democratic Republic of the Congo and Liberia. Available: https://rebuildconsortium.com/media/1625/pac00350rings-gender-and-community-brief-002.pdf [Accessed 04 Jan 2021].

9 Steege R, Taegtmeyer M, Ndima S, et al. Redressing the gender imbalance: a qualitative analysis of recruitment and retention in Mozambique's community health workforce. Hum Resour Health 2020;18:37.

10 Kane S, Kok M, Ormel H, et al. Limits and opportunities to community health worker empowerment: a multi-country comparative study. Soc Sci Med 2016;164:27-34

11 Schaaf M, Warthin C, Freedman L, et al. The community health worker as service extender, cultural broker and social change agent: a critical interpretive synthesis of roles, intent and accountability. BMJ Glob Health 2020;5:e002296.

12 Najafizada SAM, Labonté R, Bourgeault IL. Community health workers of Afghanistan: a qualitative study of a national program. Confl Health 2014;8:26.
13 Feldhaus I, Silverman M, LeFevre AE, et al. Equally able, but unequally accepted: gender differentials and experiences of community health volunteers promoting maternal, newborn, and child health in Morogoro region, Tanzania. Int J Equity Health $2015 ; 14: 70$

14 Dhatt R, Theobald S, Buzuzi S, et al. The role of women's leadership and gender equity in leadership and health system strengthening. Glob. Health Epidemiol. 2017;2:e8.

15 George A. Human resources for health: a gender analysis. background paper prepared for the women and gender equity knowledge network and the health systems knowledge network of the who Commission on social determinants of health. Geneva: World Health Organization, 2007. https://www.who.int/social determinants/resources/human_resources_for_health_wgkn_2007. pdf

16 Wurie HR, Samai M, Witter S. Retention of health workers in rural Sierra Leone: findings from life histories. Hum Resour Health 2016;14:3.

17 Bettee A, Dean L, Kollie K. The Ebola outbreak and the wider health system: understanding impact and exploring the way forward in Liberia through the case study of NTDs. Stakeholder consultation meeting report. countdown. Available: http://www.countdownonntds. org/publications/other-resources/ [Accessed 06 Jan 2021].

18 Bell SA, Munro-Kramer ML, Eisenberg MC, et al. "Ebola kills generations": Qualitative discussions with Liberian healthcare providers. Midwifery 2017;45:44-9.

19 Ling EJ, Larson E, Macauley RJ, et al. Beyond the crisis: did the Ebola epidemic improve resilience of Liberia's health system? Health Policy Plan 2017;32:iii40-7.

20 Miller NP, Milsom P, Johnson G, et al. Community health workers during the Ebola outbreak in guinea, Liberia, and Sierra Leone. $J$ Glob Health 2018;8:2.

21 Ministry of Health Liberia. National community health services policy, 2016-2021. Monrovia, Liberia: Government of Liberia.

22 Ministry of Health Liberia. Investment plan for building a resilient health system in Liberia, 2015-2021. Available: https://au.int/sites/ default/files/newsevents/workingdocuments/27027-wd-liberia-_ investment_plan_for_building_a_resilient_health_system.pdf [Accessed $06 \mathrm{Jan} 2021]$.

23 Ministry of Health and Sanitation, Sierra Leone. National community health worker policy 2016-2020. Freetown, Sierra Leone: Government of Sierra Leone.

24 WHO. Democratic Republic of the Congo key indicators, 2016. Available: https://apps.who.int/gho/data/node.cco.ki-COD?lang=en [Accessed 06 Jan 2021].

25 Snape D, Spencer L. The foundations of qualitative research. In: Ritchie J, Lewis J, eds. Qualitative research practice. A guide for social science students and researchers. Thousand Oaks: Sage Publications, 2003: 1-23.

26 Legard R, Keegan J, Ward K. In-depth interviews. In: Ritchie J, Lewis $\mathrm{J}$, eds. Qualitative research practice. A guide for social science students and researchers. Thousand Oaks: Sage Publications, 2003: 138-69.

27 Ssali SN, Theobald S. Using life histories to explore gendered experiences of conflict in Gulu district, Northern Uganda: implications for post-conflict health reconstruction. South African Review of Sociology 2016;47:81-98.

28 Witter S, Namakula J, Alonso-Garbayo A, et al. Experiences of using life histories with health workers in post-conflict and crisis settings: methodological reflections. Health Policy Plan 2017;32:czw166-601.

29 Ritchie J, Spencer L, O'Connor W. Carrying out qualitative analysis. In: Ritchie J, Lewis J, eds. Qualitative research practice: a guide for social science students and researchers. Thousand Oaks: Sage Publications, 2003: 219-62.

30 Sites de soins communautaires. Manuel de l'encadreur (Community care sites; Trainer's manual. Kinshasa, Democratic Republic of Congo: Ministry of Public Health, Democratic Republic of Congo, 2006 .

31 Ministry of Public Health, Democratic Republic of Congo. Manuel des procédures du relais communautaire, cellule d'animation communautaire et comité de développement de l'aire de santé (Community health workers, community animation groups and health centre committees' guidelines handbook. Kinshasa, Democratic Republic of Congo: Ministry of Public Health, Democratic Republic of Congo, 2007.

32 Ministry of Public Health, Democratic Republic of Congo. Manuel de procedures d'organisation et de fonctionnement des structures et approches communautaires (community organisations and approaches guidelines Handbook. Kinshasa, Democratic Republic of Congo,

2016. 
33 Modua MT. Good governance and gender. In: International organisation for migration. Geneva, Switzerland: OIM, 2003: 24-9.

34 Mumtaz Z. Gender and social geography: impact on lady health workers mobility in Pakistan. BMC Health Serv Res 2012;12:360.

35 Ahmed J, Ur Rehman S, Shahab M. Community midwives' acceptability in their communities: a qualitative study from two provinces of Pakistan. Midwifery 2017;47:53-9.

36 Nyanzi S, Manneh H, Walraven G. Traditional birth attendants in rural Gambia: beyond health to social cohesion. Afr J Reprod Health 2007; $11: 43-56$

37 Razee H, Whittaker M, Jayasuriya R, et al. Listening to the rural health workers in Papua New Guinea - the social factors that influence their motivation to work. Soc Sci Med 2012;75:828-35.

38 Mumtaz Z, Salway S, Waseem M, et al. Gender-Based barriers to primary health care provision in Pakistan: the experience of female providers. Health Policy Plan 2003;18:261-9.

39 Percival V, Dusabe-Richards E, Wurie H, et al. Are health systems interventions gender blind? examining health system reconstruction in conflict affected states. Global Health 2018;14:90.
40 Mama A. Where We Must Stand: African Women in an Age of War. OpenDemocracy, 50.50 Inclusive Democracy. Available: https://www. opendemocracy.net/en/5050/where-we-must-stand-african-womenin-age-of-war/ [Accessed 07 Jan 2021]

41 ReBUILD. How gender influences the service provided by community health worker in Sierra Leone. Available: https://www. rebuildconsortium.com/resources/how-gender-infuences-theservice-provided-by-community-health-workers-in-sierra-leone/ [Accessed 02 Jan 2021].

42 Bisung E, Elliott SJ, Abudho B, et al. Using Photovoice as a community based participatory research tool for changing water, sanitation, and hygiene behaviours in Usoma, Kenya. Biomed Res Int 2015;2015:1-10.

43 Budig K, Diez J, Conde P, et al. Photovoice and empowerment: evaluating the transformative potential of a participatory action research project. BMC Public Health 2018;18:432.

44 WHO guideline on health policy and system support to optimize community health worker programmes. Available: https://apps.who. int/iris/bitstream/handle/10665/275474/9789241550369-eng.pdf? ua $=1$ [Accessed 02 Jan 2021] 